\title{
Mechanisms of ENSO-forcing of hemispherically symmetric precipitation variability
}

\author{
By R. SEAGER ${ }^{1 *}$, N. HARNIK ${ }^{1}$, W. A. ROBINSON ${ }^{2}$, Y. KUSHNIR $^{1}$, M. TING ${ }^{1}$, \\ H.-P. HUANG ${ }^{1}$ and J. VELEZ ${ }^{1}$ \\ ${ }^{1}$ Lamont Doherty Earth Observatory of Columbia University, USA \\ ${ }^{2}$ University of Illinois at Urbana-Champaign, USA
}

(Received 22 June 2004; revised 24 November 2004)

\section{SUMMARY}

The patterns of precipitation anomalies forced by the El Niño-Southern Oscillation during northern hemisphere winter and spring are remarkably hemispherically symmetric and, in the midlatitudes, have a prominent zonally symmetric component. Observations of global precipitation variability and the moisture budget within atmospheric reanalyses are examined to argue that the zonally symmetric component is caused by interactions between transient eddies and tropically-forced changes in the subtropical jets. During El Niño events the jets strengthen in each hemisphere and shift equatorward. Changes in the subtropical jet influence the transient-eddy momentum fluxes and the eddy-driven mean meridional circulation. During El Niño events, eddy-driven ascent in the midlatitudes of each hemisphere is accompanied by low-level convergence and brings increased precipitation. These changes in the transient-eddy and stationary-eddy moisture fluxes almost exactly cancel each other and, in sum, do not contribute to the zonal-mean precipitation anomalies. Propagation of anomalous stationary waves disrupts the zonal symmetry. Flow around the deeper Aleutian Low and the eastward extension of the Pacific jet stream supply the moisture for increased precipitation over the eastern North Pacific and the western seaboard of the United States, while transient-eddy moisture convergence supplies the moisture for increased precipitation over the southern United States. In each case, increased precipitation is fundamentally caused by anomalous ascent forced by anomalous heat and vorticity fluxes.

KEYWORDS: ENSO Precipitation Symmetry

\section{INTRODUCTION}

At the equator, the precipitation anomalies associated with the El Niño-Southern Oscillation (ENSO) during boreal winter and spring are quite zonally asymmetric with, during El Niño, increased rain in the central and eastern Pacific and western Indian Ocean and reduced rain over the East Indies, northern South America, the tropical Atlantic and the eastern Indian Ocean. These precipitation anomalies are associated with anomalous diabatic forcing of the global atmosphere circulation. Despite the zonal asymmetry of the diabatic forcing the extratropical response is quite zonally symmetric. During El Niño winters there is increased precipitation across the northern midlatitudes between about $20^{\circ} \mathrm{N}$ and $60^{\circ} \mathrm{N}$. The largest increase is at the longitude of the East Pacific and the Americas but there is also increased precipitation across Asia. There is also a zonal band of increased precipitation in the southern hemisphere $(\mathrm{SH})$ centred at about $45^{\circ} \mathrm{S}$, indicating an obvious degree of hemispheric symmetry.

This pattern is shown in Figure 1(a) where the precipitation anomalies for the December-May half year, as estimated from the Global Precipitation Climatology Project (GPCP) (Huffman et al. 1997), a blend of satellite and gauge data, are regressed onto the zonal-mean zonal wind index of Seager et al. (2003a). The wind index will be described in due course but for now we just need to know that it correlates with the NINO3 SST index (the spatially averaged sea-surface-temperature anomaly between $5^{\circ} \mathrm{S}$ and $5^{\circ} \mathrm{N}$ and $150^{\circ} \mathrm{W}$ and $90^{\circ} \mathrm{W}$ ) at 0.79 , indicating that a positive wind

* Corresponding author: Lamont Doherty Earth Observatory of Columbia University, Palisades, New York 10964, USA. e-mail: rich@maatkare.ldeo.columbia.edu

(C) Royal Meteorological Society, 2005. 
Dec-May GPCP Precip to Wind Index 80-01

(a) Regression
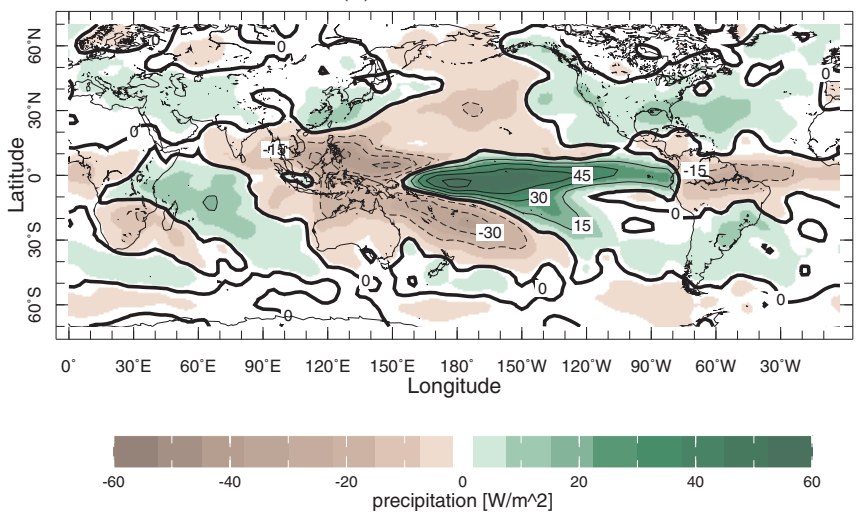

(b) Correlation
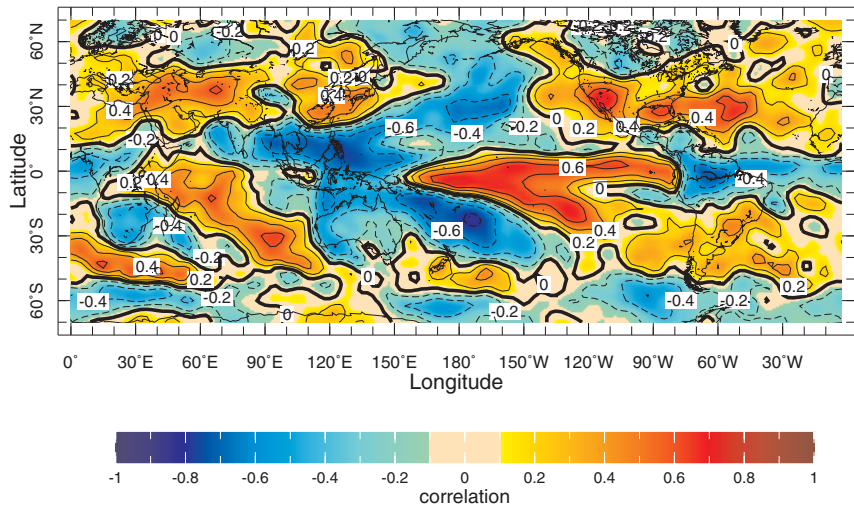

Figure 1. (a) The regression and (b) the correlation of the observed GPCP satellite-gauge precipitation for 19802001 with the wind index of Seager et al. (2003) and reflecting El Niño-related variability. The units in (a) are $\mathrm{W} \mathrm{m} \mathrm{m}^{-2}$ per standard deviation of the wind index.

index corresponds to El Niño conditions. The wind data are from National Centers for Environmental Prediction-National Center for Atmospheric Research (NCEP-NCAR) Reanalysis and the period covered is December 1979 to May 2001. Figure 1(b) shows the associated correlation. Some of these elements of ENSO-related precipitation variability were previously noted by Ropelewski and Halpert (1987, 1989, 1996), Kiladis and Diaz (1989) and Aceituno (1988) but here come into better focus because of the use of global satellite data.

At most longitudes in the northern hemisphere $(\mathrm{NH})$ the increase in midlatitude precipitation is statistically significant but significance is marginal in the $\mathrm{SH}$ (but see below). With the brevity of the satellite precipitation record (22 years are used here) correlation coefficients greater than 0.404 are statistically significant at the $95 \%$ level. The zonally symmetric component of ENSO-related precipitation anomalies has been remarked on before. Wallace and Jiang (1987) noted that 'the observed wintertime northern hemisphere response to El Niño exhibits a remarkable amount of circular symmetry' which was 'in contrast to the teleconnection patterns' they then discussed, 
such as the Pacific-North America (PNA) pattern (Wallace and Gutzler 1981). Karoly (1989) stated that, during an El Niño event during SH summer 'there are stable zonally symmetric anomalies of the SH circulation with increased height and temperature at low latitudes and decreased height in middle latitudes'. Seager et al. (2003a) have provided an explanation for the zonal symmetry, and for midlatitude cooling during El Niño events, in terms of interactions between transient-eddy propagation and the mean meridional circulation. Lau et al. (2005) have diagnosed a similar mechanism in an atmosphere general-circulation model (GCM), including the hemispheric symmetry, but also argue that interactions between heating over the Indian Ocean and the Pacific storm-track can lead to zonally elongated anomalies in the NH. These studies addressed the atmospheric circulation and temperature responses but not the precipitation.

The extensive midlatitude NH drought between 1998 and 2002 discussed by Hoerling and Kumar (2003) (see also Barlow et al. (2002)), and which had its SH counterpart, is related to the ENSO response pattern through the persistent La Niña conditions during this time, even as the anomalous warmth of parts of the Indian Ocean may also play a role. The ENSO response pattern is also very similar to the pattern found in the modelling study of Schubert et al. (2004) to be related to the Dust Bowl drought of the 1930s, a time of persistent but weak La Niña (Seager et al., manuscript submitted to Journal of Climate).

El Niño-related precipitation anomalies around the world can be caused by tropical forcing of large-scale Rossby waves that propagate into higher latitudes (e.g. Horel and Wallace 1981; Hoskins and Karoly 1981; Webster 1981; Sardeshmukh and Hoskins 1988; Trenberth et al. 1998). For example, the anomalous Rossby wave train extending north and east from the tropical Pacific during El Niño events causes the North Pacific storm-track to extend further east and also to adopt a course further to the south (Trenberth et al. 1998; Wang and Ting 2000). However, a detailed examination of the mechanisms responsible for the related precipitation anomaly has not yet been offered. Furthermore, the causes of the zonal symmetry need more study and probably involve dynamics distinct from Rossby wave teleconnections.

In the current work we seek to explain the physical mechanisms that cause the midlatitude precipitation variability shown in Figure 1. We will use the NCEP-NCAR Reanalysis data (Kalnay et al. 1996; Kistler et al. 2001; hereafter 'the Reanalysis'). There are well-publicized errors in the moisture budget of the Reanalysis (Trenberth and Guillemot 1998) but it will be shown that much can be learned through its analysis about mechanisms of precipitation variability. We will then evaluate the contributions to ENSO-related global precipitation anomalies from evaporation, stationary and transient eddies, and the zonal-mean meridional circulation. Changes in the contribution of these terms to the convergence and divergence of column-integrated moisture will then be related to changes in the atmosphere circulation. We will begin by analysing the zonally symmetric variability and continue by examining regional aspects, in particular the causes of precipitation variability over North America.

It will be claimed that a complete explanation of ENSO forcing of extratropical precipitation variability requires interactions between transient eddies and tropically forced changes in the subtropical jets to explain the zonally symmetric component and forced stationary waves, and their interaction with storm-tracks, to explain departures from symmetry. Section 2 and the appendix examine the reliability for our purpose of the NCEP-NCAR Reanalysis, section 3 briefly reviews the climatological moisture budget, section 4 examines the zonally symmetric variability, section 5 examines the regional variability and section 6 examines how well these patterns are captured in a climate model. Discussion and Conclusions are offered in the final two sections. 


\section{THE PATTERN OF ENSO-RELATED PRECIPITATION VARIABILITY IN THE NCEP-NCAR REANALYSIS}

In the current work we examine the Reanalysis estimates of ENSO-related precipitation variability and determine the mechanisms of variability by analysing the terms within the Reanalysis moisture budget and relating them to circulation variability. The appendix contains a detailed assessment of how reliable the Reanalysis is for this kind of work, and concludes that it does contain useful information regarding many of the features of the precipitation variability of interest here.

The precipitation field reported within the Reanalysis is not consistent with the Reanalysis moisture budget (see appendix). Here we derive a precipitation field, $P_{\mathrm{der}}$, that is consistent with the Reanalysis moisture budget using:

$$
P_{\mathrm{der}}=E-\frac{L}{g a \cos \phi} \int_{0}^{p_{\mathrm{s}}}\left(\frac{\partial \bar{u} \bar{q}}{\partial \lambda}+\frac{\partial(\bar{v} \bar{q} \cos \phi)}{\partial \phi}+\frac{\partial \overline{u^{\prime} q^{\prime}}}{\partial \lambda}+\frac{\partial\left(\overline{v^{\prime} q^{\prime}} \cos \phi\right)}{\partial \phi}\right) \mathrm{d} p .
$$

Here $E$ is the surface latent-heat flux, $p$ and $p_{\mathrm{s}}$ are the pressure and surface pressure, $u$ and $v$ are the zonal and meridional velocities along pressure surfaces, $q$ is the specific humidity, $L$ is the latent heat of condensation, $g$ is the gravitational acceleration, $a$ is the radius of the Earth, $\lambda$ is longitude, $\phi$ is latitude, overbars denote monthly mean quantities and primes denote departures from the monthly mean. To evaluate $P_{\text {der }}$ we used the gridded data and centred differences. The first two terms within the integral are the divergence of moisture by the monthly mean flow (here containing both the stationary waves and the zonal-mean meridional circulation) and the second two are the divergence by transient eddies. $P_{\text {der }}$ is here called the NCEP-derived precipitation and is that precipitation implied by the Reanalysis moisture budget. Although both it and $E$ have units of $\mathrm{W} \mathrm{m}^{-2}$, i.e. energy per square metre per second, we refer to them henceforth as simply precipitation and evaporation.

Figure 2 shows the regression and correlation of $P_{\text {der }}$ on the wind index, to be compared with Fig. 1. $P_{\text {der }}$ reproduces the significant correlation of precipitation in the northern hemisphere from the eastern North Pacific across North America to the Atlantic Ocean but misses the significant correlation over Asia. Despite being less coherent than in the satellite data, a band of positive correlation of $P_{\text {der }}$ remains in the southern midlatitudes, although the significance is mostly marginal. As can also be seen in Fig. 2, the amplitudes of the $P_{\text {der }}$ anomalies are generally reasonable.

Much of the work to be described involves the zonally symmetric signal, and in Fig. 3 we show the regression of the zonal means of $P_{\text {der }}$ on the wind index. There is a significant zonal-mean precipitation signal with hemispheric symmetry. During an El Niño event it is wet at the equator, dry in the subtropics and wet in the midlatitudes of each hemisphere (despite the opposite seasonality). For the SH, this result argues that the more questionable correlations seen in the spatial map of Fig. 2 are indeed hinting at something real: there are significant zonal-mean precipitation changes associated with ENSO, both north and south of the equator.

The comparisons of NCEP-derived, NCEP and GPCP precipitation presented in the appendix, together with the analyses in this section, make clear that some aspects of the variations of the NCEP precipitation derived to be consistent with the moisture budget are sufficiently realistic that it makes logical sense to examine the components of the moisture budget that are responsible. This includes the zonal-mean, hemispherically symmetric, signal that brings increased precipitation to the midlatitudes during El Niño. It also includes the increased precipitation from the eastern North Pacific, passing over North America, to the North Atlantic. On the other hand the statistically significant 
(a) Regression
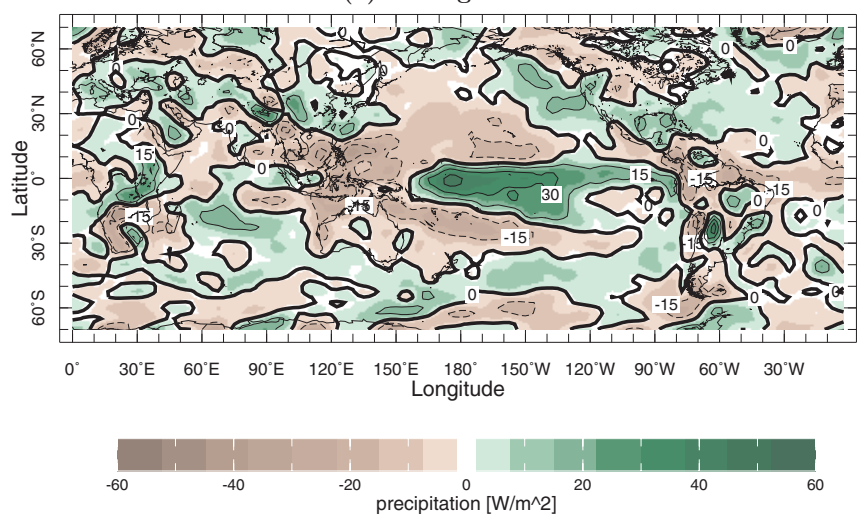

(b) Correlation
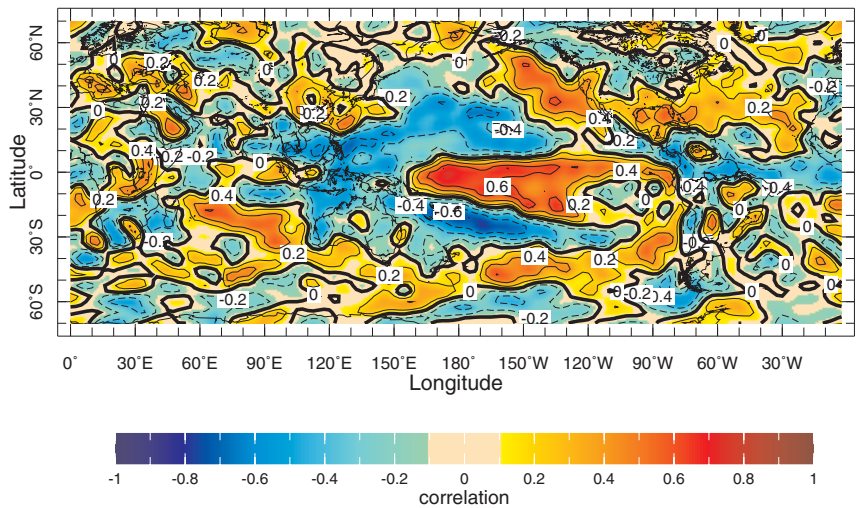

Figure 2. The (a) regression and (b) correlation between the wind index and the December-May precipitation derived to be consistent with the NCEP moisture budget, for the 1980 to 2001 period. Units for (a) are W m ${ }^{-2}$ per unit standard deviation of the wind index.

increase in observed precipitation over Asia is not captured in the derived precipitation and there is no point in using the Reanalysis to examine the mechanisms responsible.

\section{A BRIEF REVIEW OF THE CLIMATOLOGICAL ZONAL-MEAN MOISTURE BUDGET}

Before examining the nature and causes of extratropical precipitation variability it is worthwhile reviewing those aspects of the climatological moisture balance which will be useful when considering the interannual variations. More detailed analysis can be found in Peixoto and Oort (1992) and Trenberth and Stepaniak (2003) (and references to work by the same authors contained therein). The zonal-mean precipitation derived from the moisture budget, $\left\langle P_{\mathrm{der}}\right\rangle$, is given by the zonal mean of Eq. (1):

$$
\begin{aligned}
\left\langle P_{\text {der }}\right\rangle=\langle E\rangle-\frac{L}{g a \cos \phi} \int_{0}^{p_{\mathrm{s}}}\left(\frac{\partial}{\partial \phi}\langle\bar{v}\rangle\langle\bar{q}\rangle \cos \phi\right. & \\
& \left.+\frac{\partial}{\partial \phi}\left\langle\bar{v}^{*} \bar{q}^{*}\right\rangle \cos \phi+\frac{\partial}{\partial \phi}\left\langle\overline{v^{\prime} q^{\prime}}\right\rangle \cos \phi\right) \mathrm{d} p .
\end{aligned}
$$

In this equation \langle\rangle denotes the zonal mean, ${ }^{*}$ departures from the zonal mean. The first term on the right within the integral is the moisture flux divergence by the mean 
Zonal Dec-May Precipitation

(a) Correlation with Wind Index

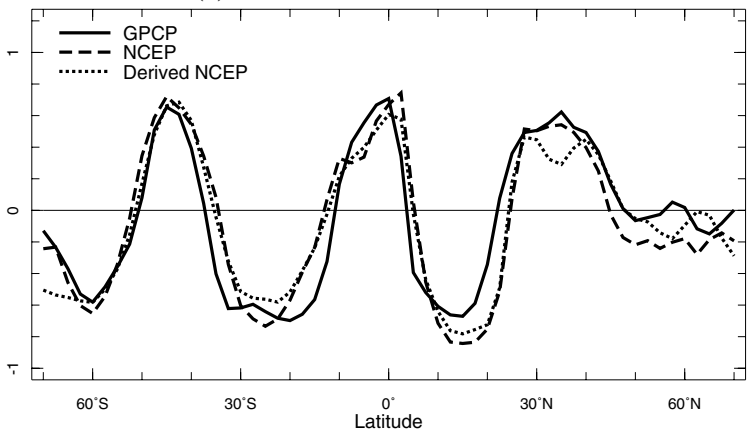

(b) Regression on Wind Index

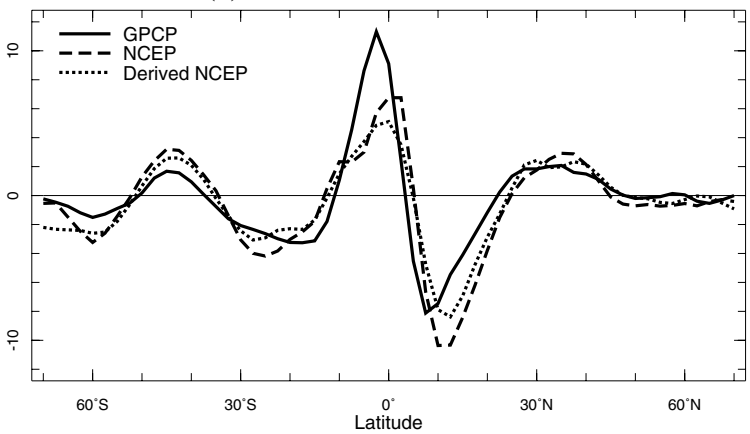

Figure 3. The (a) correlation and (b) regression coefficients between the wind index and the zonal-mean December-May precipitation as given by GPCP, the NCEP precipitation and the precipitation derived to be consistent with the NCEP moisture budget. Units for (b) are $\mathrm{W} \mathrm{m}^{-2}$ per unit standard deviation of the wind index.

meridional circulation (MMC), the second is the divergence of moisture by stationary eddies and the third is the divergence of moisture by transient eddies on sub-monthly timescales (computed from daily data). The vertical integration is performed using standard discretization techniques from the highest Reanalysis level reporting specific humidity to $p_{\mathrm{s}}$, thus ignoring Reanalysis levels below ground. As before, the units of each term are $\mathrm{W} \mathrm{m} \mathrm{m}^{-2}$.

Each of the terms in Eq. (1) was evaluated from the NCEP-NCAR Reanalyses over the period from 1979 to 2001 . This period was chosen because of the incorporation of satellite data in 1979 that greatly improves the SH data coverage.

The balance will be illustrated for the same half year, December-May, for which we examine the variability. Figure 4(a) compares the latitudinal distributions of $\left\langle P_{\text {der }}\right\rangle$, $\langle E\rangle$ and the GPCP precipitation. $\left\langle P_{\text {der }}\right\rangle$ has a double peak in the tropics and smaller peaks in the extratropics of each hemisphere. In contrast, $\langle E\rangle$ has a minimum at the equator (Seager et al. 2003b) but otherwise decreases smoothly from the tropics into the midlatitudes. The extratropical $\left\langle P_{\text {der }}\right\rangle$ maxima can be largely sustained by the local $\langle E\rangle$ but atmospheric transport of moisture must be responsible for $\left\langle P_{\text {der }}\right\rangle$ exceeding $\langle E\rangle$ poleward of about $40^{\circ} \mathrm{N}$ and $\mathrm{S}$ and for $\langle E\rangle$ exceeding $\left\langle P_{\text {der }}\right\rangle$ equatorward of there.

Figure 4(b) shows $\left\langle P_{\text {der }}\right\rangle$ along with both the convergence of moisture by the MMC and the convergence by transient eddies. In the tropics the MMC contributes constructively to the $\left\langle P_{\text {der }}\right\rangle$ distribution. Near the equator, rising motion in the convergence zones 
Dec-May Climatology $(\mathrm{W} / \mathrm{m} 2)$

(a) Derived NCEP, GPCP Precipitation, and Evaporation

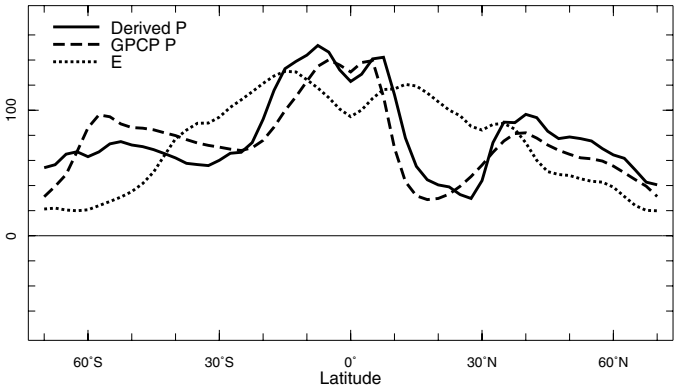

(b) Derived NCEP Precipitation, Transient Eddies, and MMC

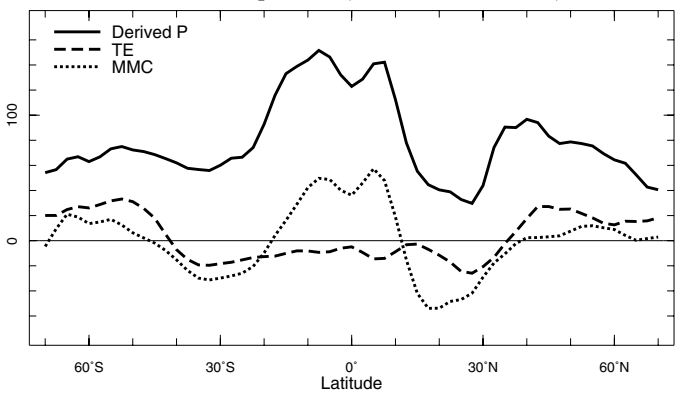

(c) Derived NCEP Precipitation, Transient Eddies, and Stationary Eddies

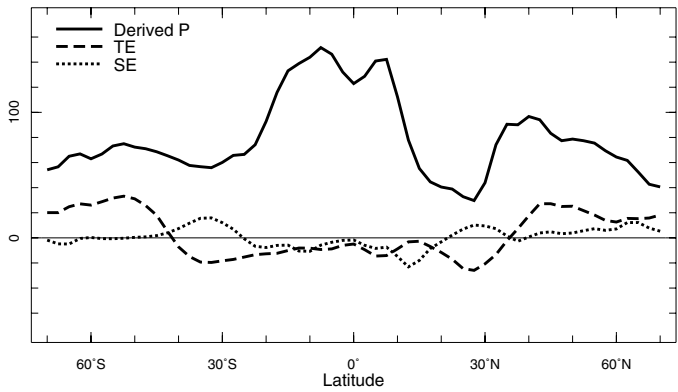

Figure 4. The zonal-mean climatological derived precipitation (consistent with the NCEP moisture budget) and terms in the zonal-mean moisture budget (see Eq. (2)) for December-May. The zonal-mean derived precipitation is shown in each panel. (a) also shows the GPCP observed precipitation and the zonal-mean evaporation, (b) shows the vertical-mean convergences of moisture by the transient eddies and the mean meridional circulation and (c) shows the vertical-mean convergences of moisture by the transient and stationary eddies. Except for the observed precipitation, all data are from the NCEP-NCAR Reanalysis data for the period from 1979 to 2001 . Units are $\mathrm{W} \mathrm{m} \mathrm{m}^{-2}$.

and monsoons contributes moisture and $\left\langle P_{\text {der }}\right\rangle$ is in excess of $\langle E\rangle$. In the subtropics, descent in the Hadley cell and subtropical anticyclones contributes drying, and $\langle E\rangle$ is in excess of $\left\langle P_{\text {der }}\right\rangle$. Transient eddies contribute a weak moisture divergence, or drying, within the tropics. In the extratropics both the transient eddies and the MMC converge moisture slightly poleward of the $\left\langle P_{\text {der }}\right\rangle$ maximum.

Figure 4(c) shows the stationary-eddy moisture flux convergence with, for reference, the transient-eddy convergence. The SH subtropical anticyclones are well developed at this time (Rodwell and Hoskins 2001; Seager et al. 2003c). Through poleward 
advection of moist air on their western side and equatorward advection of drier air on their eastern side, the subtropical anticyclones converge moisture between $30^{\circ} \mathrm{S}$ and $40^{\circ} \mathrm{S}$. In the $\mathrm{NH}$ the equatorward flow in the winter monsoon, extending from West Africa across Asia, of air that is drier than the zonal mean contributes strongly to moisture convergence by the stationary waves at about $25^{\circ} \mathrm{N}$. Poleward of here, moist poleward flow on the eastern flanks of the Aleutian and Icelandic Lows, and dry equatorward flow on the western flanks, diverge moisture away from the $30^{\circ}-40^{\circ} \mathrm{N}$ latitude band and converge it to the north.

A striking feature is the near-complete cancellation of the transient-eddy moisture flux divergence around $25^{\circ}-40^{\circ} \mathrm{N}$ and $\mathrm{S}$ by stationary-wave convergence. This allows for the 'seamless' poleward transport of moisture discussed by Trenberth and Stepaniak (2003). The subtropical stationary eddies converge moisture where the atmosphere is statically stable, subsiding and with little precipitation (see Figures 2 and 3 of Seager et al. (2003c)). Converging moisture cannot readily be converted into precipitation in such an environment and the transient eddies, which tend to act diffusively on the temperature and humidity distribution, diverge the moisture away. Further poleward in the NH both the transient eddies and the Aleutian and Icelandic Lows move moisture poleward and converge it north of $40^{\circ} \mathrm{N}$. Here there is mean vertical ascent, as can be deduced from the MMC contribution in Figure 4(b), and the eddy convergence can be converted into precipitation.

The moisture convergences by the transient eddies and the MMC act constructively in the midlatitudes. The transient-eddy heat and momentum flux convergences both force ascent poleward of about $40^{\circ}$ and descent equatorward. Consequently the eddydriven $\mathrm{MMC}$, forced by each of these processes, has low-level moisture convergence poleward of $40^{\circ}$ and low-level moisture divergence equatorward of there, augmenting the contributions by the transient-eddy moisture fluxes. These interrelationships continue to hold for the contributions to the anomalous precipitation.

\section{MECHANISMS OF TROPICAL FORCING OF ZONAL-MEAN PRECIPITATION VARIABILITY}

\section{(a) Methodology for examination of interannual precipitation variability}

Section 2 demonstrated that the derived precipitation, i.e. that which is consistent with the NCEP moisture budget, captures much of the ENSO-forced extratropical precipitation variability. Therefore, the moisture budget within the Reanalysis can be used to understand the mechanisms responsible. To do this, monthly anomalies were computed, using Reanalysis data, of the five terms in the zonal-mean moisture budget of Eq. (2). December-May anomalies were then formed by averaging monthly anomalies.

All quantities are regressed onto the so-called wind index of Seager et al. (2003a, hereafter S03). It is based on a principal component analysis of the $300 \mathrm{mb}$ zonal-mean zonal wind performed such that the eigenvectors (Empirical Orthogonal Functions, or EOFs) are in the latitude-calendar-month domain with a different time coefficient every year. The first EOF captures variability that is approximately hemispherically symmetric (see S03). A positive value of the associated time series - the wind index-corresponds to El Niño conditions. The principle component only has one value per year since the monthly evolution within the year is described by the EOF pattern. Although we could get the same results as presented here by regressing on NINO3 we use the wind index for consistency with S03. The period used is from December 1978 to May 2001 (and hence is slightly longer than was available for the GPCP data used in Fig. 3). 


\section{(b) Contributions to the zonal-mean precipitation variability}

The regressions on the wind index of the terms in the moisture budget are plotted in Fig. 5. The precipitation anomalies are not purely accounted for by local evaporation anomalies (Fig. 5(a)). Instead, anomalous moisture convergence by the MMC explains most of the zonal structure of the precipitation anomalies (Fig. 5(b)). In the tropics this is because the MMC is the dominant term: as the Hadley cell intensifies, and the intertropical convergence zone (ITCZ) moves equatorward from its usual location just north of the equator, moisture convergence increases at the equator (where there is anomalous ascent) and decreases in the subtropics (where there is anomalous descent). Outside of the tropics the MMC explains the precipitation anomalies because the transient-eddy and stationary-eddy convergences, though each individually large, essentially cancel each other. In midlatitudes the anomalous MMC dries the subtropics and moistens the midlatitudes, largely because it strengthens during El Niño events (S03). By comparison with the climatological patterns (Fig. 4(b)) it can also be seen that the MMC moisture convergence moves equatorward in both hemispheres causing the midlatitude precipitation maxima to also shift equatorward during El Niño events.

The extensive cancellation in the subtropics and midlatitudes between the anomalous moisture flux convergences by the transient and stationary eddies (Fig. 5(c)) allows the continued operation of the 'seamless' total poleward transport (Trenberth and Stepaniak

The transient-eddy moisture flux convergence anomaly dries the subtropics and moistens the midlatitudes while the stationary-eddy moisture flux convergence does the opposite. The stationary-eddy convergences centred at $25^{\circ} \mathrm{N}$ and $\mathrm{S}$ are primarily caused by the anomalous low-pressure cells over the north-east and south-east Pacific forced by anomalous transient-eddy momentum flux convergence (Hoerling and Ting 1994). These lows cause increased equatorward advection of relatively moist air over the central Pacific and increased poleward advection of relatively dry air over the eastern Pacific - an anomalous equatorward moisture transport. The moisture convergences at around $25^{\circ} \mathrm{N}$ and $\mathrm{S}$ are compensated by increased transient-eddy divergence within the Pacific storm-tracks. In both hemispheres between $30^{\circ}$ and $45^{\circ}$, the anomalous moisture divergence caused by the anomalous low-pressure cells is cancelled by anomalous transient-eddy moisture flux convergence. The stationary-wave convergence poleward of $50^{\circ} \mathrm{N}$ is also caused by the stronger than usual Aleutian Low, because at this latitude the moistest air is off the coast of British Columbia and Alaska where there is anomalous southerly flow.

\section{(c) Interactions between transient eddies and the MMC, and generation of extratropical precipitation variability}

The moisture transport within the MMC best explains increased midlatitude precipitation during El Niño in both hemispheres. Next we briefly restate the argument of S03 for how the anomalous MMC is caused by an anomalous transient-eddy momentum flux that causes eddy-driven ascent ( $\mathrm{S} 03$ ).

The all-important element is the strengthening of the subtropical jet streams in each hemisphere. This provides the link between the changes in tropical SST and the changes in the transient-eddy fluxes. Using observational analysis and a linear quasi-geostrophic model, S03 show that the stronger subtropical jets during El Niño create regions of anomalously positive meridional gradient of potential vorticity (PV) immediately poleward, and anomalously negative gradient further poleward of that. They show that transient eddies, propagating in the latitude-height plane, are refracted away from the 
Dec-May Regression on Wind Index (W/m2)

(a) Derived NCEP Precipitation and Evaporation

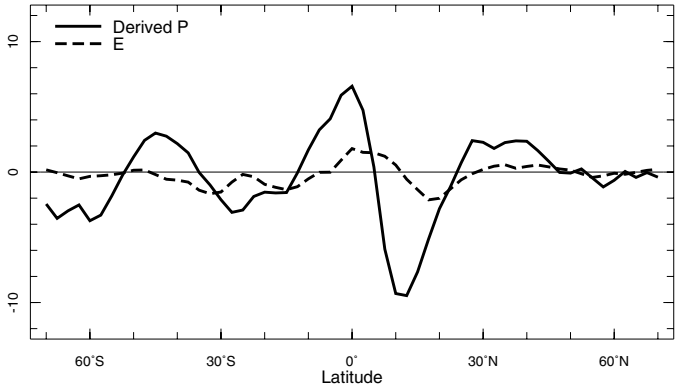

(b) Derived NCEP Precipitation, Transient Eddies, and MMC

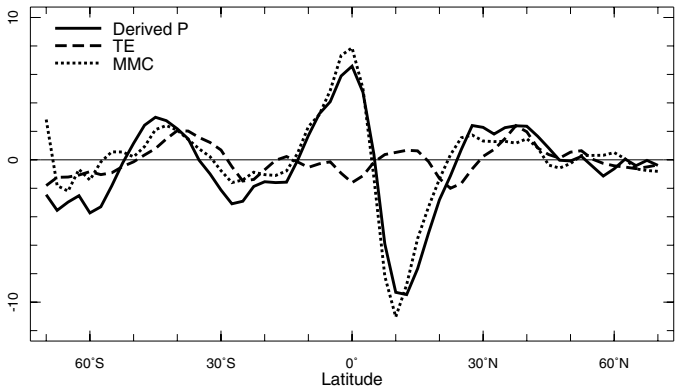

(c) Derived NCEP Precipitation, Transient Eddies, and Stationary Eddies

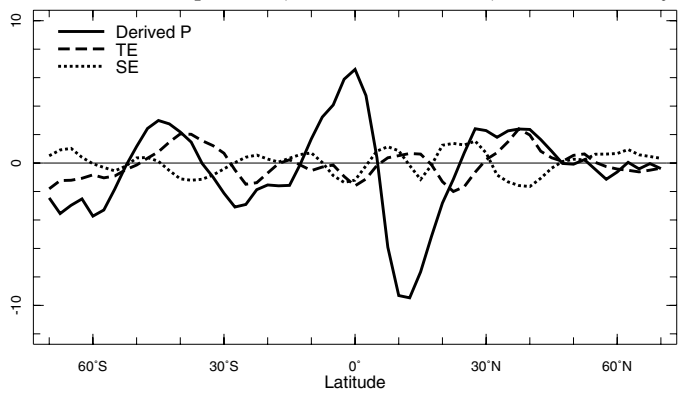

Figure 5. The NCEP-NCAR derived precipitation, and terms in the vertically integrated moisture budget, regressed onto the wind index for December-May. The precipitation is shown in each panel, (a) shows the evaporation, (b) the contributions of moisture convergence by transient eddies and the MMC and (c) the contributions of moisture convergence by transient and stationary eddies. Units are $\mathrm{W} \mathrm{m}^{-2}$.

region of weaker PV gradient and towards the region of higher gradient, i.e. deeper into the tropics. This creates anomalies in transient-eddy momentum flux in the upper troposphere which are balanced by the Coriolis torque associated with anomalous meridional winds. The meridional divergence of these winds drives anomalous ascent in midlatitudes. S03 show that this ascent causes midlatitude cooling from the upper troposphere to near the surface in both hemispheres. According to the analysis here, the ascent also causes precipitation.

(d) Transient-eddy and stationary-wave moisture fluxes and their cancellation

Associated with the subtropical jet strengthening during El Niño there is an increase in the poleward transient-eddy moisture flux (Fig. 6(a)) at the latitudes where the 
Dec-May Regression on Wind Index

(a) $\mathrm{V}^{\prime} \mathrm{Q}^{\prime}$ (contour 10,000), Temperature (colour)
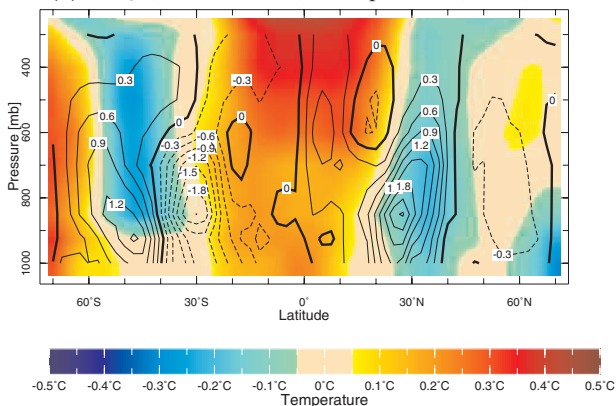

(b) $\mathrm{V}^{\prime 2}$ (contour), Zonal Wind (colour)

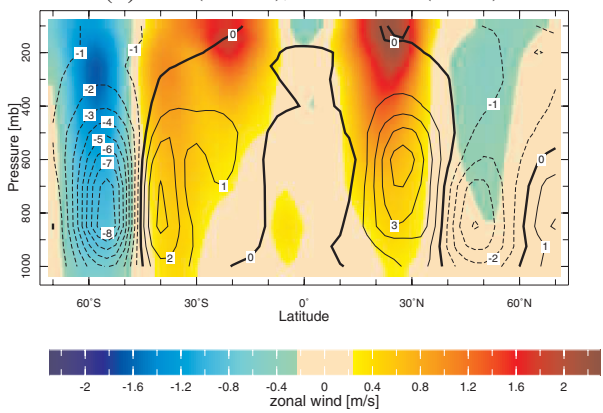

(c) $\mathrm{V}^{*} \mathrm{Q} *($ contour $* 10,000)$, Specific Humidity (colour)

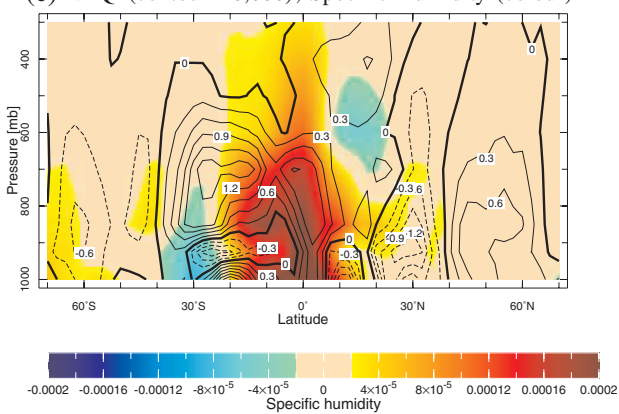

Figure 6. (a) The zonal means of temperature (colours, $\mathrm{K}$ ) and $\overline{v^{\prime} q^{\prime}}$ (contours, $\mathrm{m} \mathrm{s}^{-1}$ times $10^{4}$ ), (b) the zonal means of zonal wind (colours, $\mathrm{m} \mathrm{s}^{-1}$ ) and $\overline{v^{\prime 2}}$ (contours, $\mathrm{m}^{2} \mathrm{~s}^{-2}$ ) and (c) the zonal means of the specific humidity (colour, $\mathrm{kg} / \mathrm{kg}$ ) and $\left\langle\overline{v^{*} q^{*}}\right\rangle$, all regressed onto the wind index, for December-May.

meridional temperature gradient and wind shear (Fig. 6(b)) strengthen (about $30^{\circ} \mathrm{N}$ and S). The transient-eddy moisture flux decreases further poleward so this is an equatorward shift of the typical pattern*.

* The increased temperature gradient and wind shear in the subtropics are a result of the tropical heating plus the midlatitude cooling induced by the transient-eddy momentum flux. In the NH the latitude of increased eddy activity and increased eddy moisture transport corresponds to the latitude of the increased subtropical jet and increased vertical shear of the zonal-mean zonal wind (Fig. 6). In the SH, although there are increases in eddy activity and moisture transport at the latitude of the increased subtropical jet, the largest increase occurs poleward where there is a second area of stronger zonal-mean zonal wind that extends from the tropopause to the surface. This strengthening bears the hallmarks of being 'eddy-driven' (Lee and Kim 2003) and must arise as part of the eddy-mean flow interactions that cause the cooling of the southern midlatitudes. 
The latitude-height pattern of the regression on the wind index of $\overline{v^{\prime 2}}$, a measure of transient-eddy activity, shows (Fig. 6(b)) an equatorward shift with prominent areas of increase co-located with the increases in shear and transient-eddy moisture flux. This increase in eddy activity is primarily responsible for the increased moisture flux-the increase in the amount of atmospheric moisture is confined too close to the equator to be available for transport by transient eddies and is small (Fig. 6(c)). Fig. 6(c) also shows the change in the stationary-wave flux of moisture and makes clear the degree of cancellation of this with the transient-eddy flux. During ENSO cycles the preferred latitudes of the transient and stationary eddies move equatorward and poleward in consort, evidence for a dynamical interplay between the two.

\section{(e) Summary}

The zonal-mean picture is now clear. The subtropical jet strengthening during El Niño impacts the propagation of transient eddies in the upper troposphere, and their associated momentum transports, driving ascent in midlatitudes that brings increased precipitation. At the same time the patterns of transient- and stationary-eddy flux convergences shift equatorward relative to their climatological positions with increased transient-eddy flux in the subtropics being associated with stronger jets that increase the baroclinicity in the subtropics. However, at all latitudes the transient-eddy moisture transports are almost entirely cancelled by the stationary-eddy transports. This can be explained by a simple equatorward shift of both the storm-track and the stationary eddies during El Niño. Because of this cancellation the precipitation anomalies closely track the moisture convergence by the MMC.

\section{MECHANISMS OF TROPICAL FORCING OF REGIONAL PRECIPITATION VARIABILITY}

In addition to the zonally symmetric component of the precipitation variability associated with ENSO, there are important zonal asymmetries. As can be seen in Figure 1, in the northern midlatitudes the increase in rain during El Niño is greatest in the region stretching from the eastern Pacific Ocean and over North America to the eastern Atlantic Ocean. In this section we attempt to explain the regional localization of the tropically forced precipitation variability.

Figure 7 shows the zonal wind at $300 \mathrm{mb}$ and $\overline{v^{\prime 2}}$ at $850 \mathrm{mb}$ (corresponding to the level of maximum $\overline{v^{\prime} q^{\prime}}$ ) regressed onto the wind index for December-May. Amidst clear hemispheric and zonal symmetry, during El Niño, the subtropical jets are strengthened the most from the central Pacific to the western North Atlantic. The Pacific strengthening is consistent with the Gill (1980)-type response to tropical heating and also with the subtropical part of the PNA teleconnection (Wallace and Gutzler 1981; Trenberth et al. 1998). The tropical warming is maximum in this area (e.g. S03) which could also strengthen the jets locally. The increase in $\overline{v^{\prime 2}}$ at the same latitude as the northern jet, and decrease further north, is striking. It is not only in the Pacific but is also clear over the western Atlantic, consistent with the model results of Merkel and Latif (2002). It represents an eastward extension of the Pacific storm-track and a less distinct region of lesser eddy activity between it and the Atlantic storm-track. Decreases in $\overline{v^{\prime 2}}$ poleward of the latitudes of increase shows that the anomalies are caused by an equatorward shift in eddy activity, in both hemispheres. 
Dec-May Regression on Wind Index

(a) $300 \mathrm{mb} \mathrm{U}$

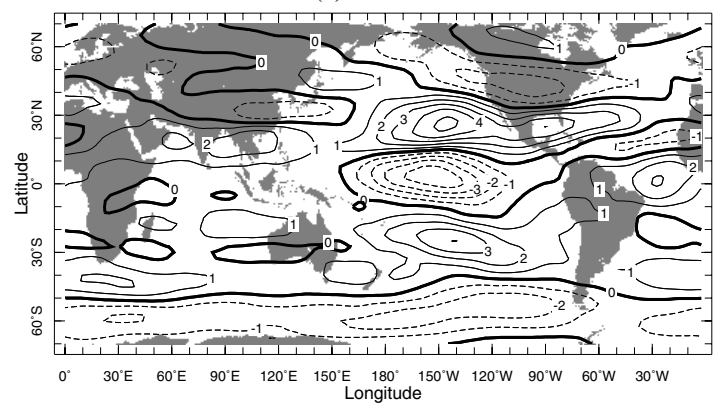

(b) $850 \mathrm{mb} \mathrm{V}^{62}$

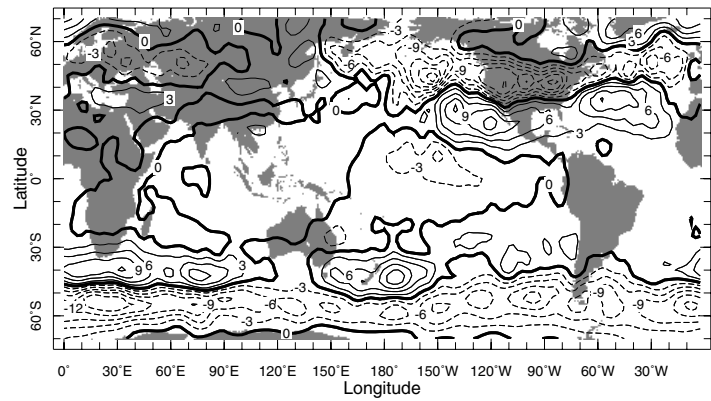

$850 \mathrm{mb}$

Figure 7. (a) The $300 \mathrm{mb}$ zonal wind (contours, $\mathrm{m} \mathrm{s}^{-1}$ ) and (b) the variance of the $850 \mathrm{mb}$ meridional velocity, $\overline{v^{\prime 2}}$, (contours, $\mathrm{m}^{2} \mathrm{~s}^{-2}$ ), regressed onto the wind index for December-May.

\section{(a) Analysis of the regional atmospheric moisture budget}

Thinking in terms of the MMC is not useful in explaining regional precipitation anomalies because meridional convergence or divergence is, to first order, balanced not by vertical motion but by zonal divergence or convergence. Instead we determined the contributions of the mean circulation and the transients to the total, zonal plus meridional, convergence of moisture. This involved summing the first two terms and last two terms, respectively, inside the integral in Eq. (1), taking anomalies, and regressing on the wind index. The sum of these terms must balance the derived precipitation minus evaporation, $P_{\mathrm{der}}-E$. Results are shown in Fig. 8.

Looking at the region from the North Pacific Ocean over North America to the North Atlantic Ocean, increased $P_{\text {der }}-E$ over the eastern North Pacific and into western North America is sustained by mean flow convergence. This is partly due to flow around the deeper Aleutian Low and partly due to the North Pacific jet extending further east. Northerly flow west of the deeper Aleutian Low reduces $P_{\mathrm{der}}-E$ in the central Pacific. The mean flow convergence, associated with stronger westerlies over the western part of the basin (Fig. 7(a)) and general southerly low-level flow, also increases $P-E$ over the North Atlantic Ocean. The transient-eddy convergence adds to increased $P_{\text {der }}-E$ on the west coast of North America and contributes the increased $P_{\mathrm{der}}-E$ in the south-eastern United States. In the SH the mean flow and transienteddy convergences act constructively to provide a band of increased $P_{\mathrm{der}}-E$ centred on $40-50^{\circ} \mathrm{S}$ that is essentially zonally symmetric. 
Regression of Dec-May to Wind Index 79-01

(a) Mean Flow Moisture Convergence Surface to $300 \mathrm{mb}$

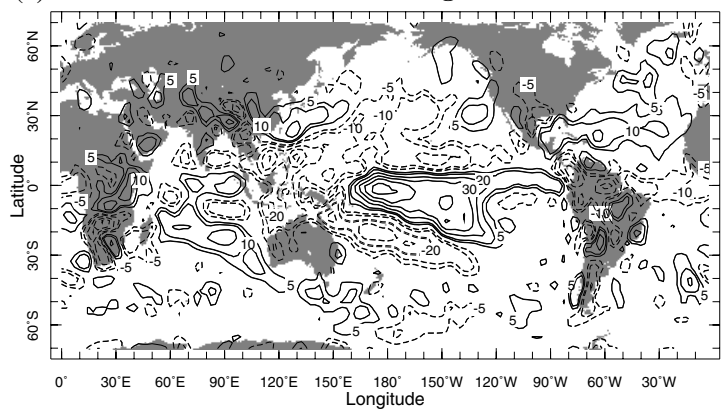

(b) Transient Eddy Moisture Convergence Surface to $300 \mathrm{mb}$

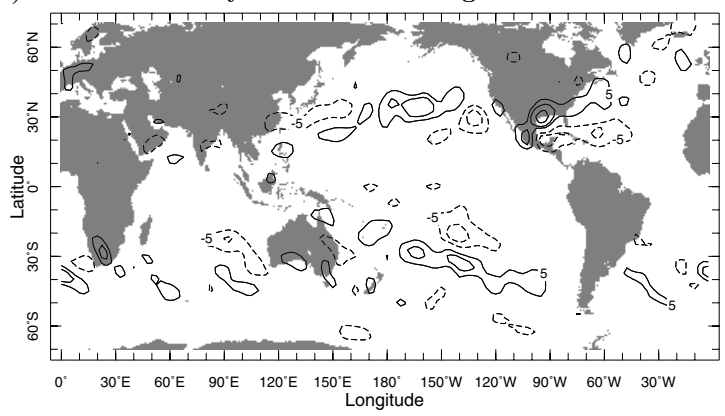

(c) Surface Evaporation

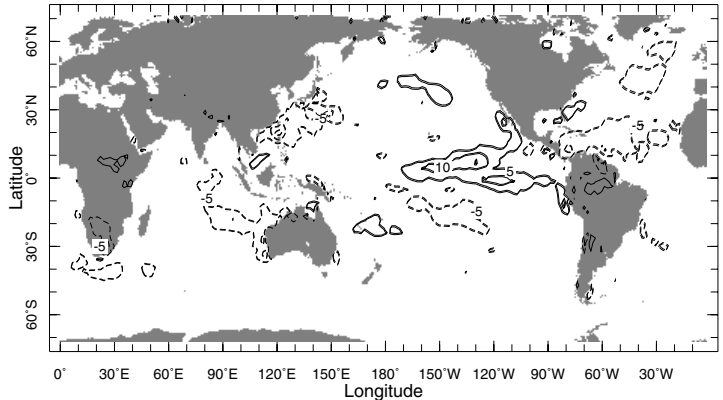

Figure 8. Vertical integrals of the horizontal convergence of moisture by (a) the mean circulation and (b) the transient eddies $\left(\mathrm{m} \mathrm{s}^{-1}\right.$ multiplied by $10^{6}$ ) and (c) the surface evaporation, all regressed onto the wind index for December-May. Units are $\mathrm{W} \mathrm{m}^{-2}$ per standard deviation of the wind index. Contours are plotted every $10 \mathrm{~W} \mathrm{~m}^{-2}$ but with additional contours for plus and minus $5 \mathrm{~W} \mathrm{~m}^{-2}$. The zero contour is suppressed in all panels.

In both the eastern North Pacific to North Atlantic region and the southern midlatitudes, the moisture flow convergence is larger than the surface evaporation anomalies (Fig. 8(c)). The surface evaporation pattern is also not systematically related to the precipitation pattern. Consequently the patterns of moisture convergence by the atmospheric flow identified can, to first order, be thought of as balancing $P_{\text {der }}$ rather than $P_{\text {der }}-E$. 
(b) A vertical velocity perspective on extratropical precipitation anomalies in the North American sector

This analysis identifies the moisture transport anomalies that sustain the precipitation anomalies. However, it is incorrect to think that anomalous moisture convergence, by the mean or transient flow, causes precipitation anomalies. For example, during El Niño events, increased rain in the central tropical Pacific is fundamentally caused by surface ocean warming and an increase in the moist static energy of surface air, which causes convective instability, rather than by the increased moisture convergence. In the extratropics it is also possible that increased precipitation is driven by processes that drive increased ascent with the anomalous moisture-flux convergence playing a secondary role in stepping in to supply the moisture required. For example, in the climatology in the subtropics, the transient-eddy moisture-flux divergence balances the stationary-eddy convergence because this is a region of descent, and moisture fluxes cannot be converted into precipitation. Similarly, in the zonal mean, the fundamental cause of increased midlatitude precipitation during El Niño events is the anomalous transient-eddy momentum flux that induces ascent. Can we say what induces regional ascent?

The most obvious regionalization of ENSO-related precipitation anomalies in the midlatitudes occurs in the longitude sector of the Americas, especially around North America. Figure 9(a) shows the vertical pressure velocity at $700 \mathrm{mb}$ regressed onto the wind index for the December-May half year. Comparing with Fig. 2, it is clear that regions of increased precipitation, as estimated by $P_{\text {der }}$, correlate with regions of anomalous ascent with centres west of the United States and over the subtropical and midlatitude Atlantic Ocean. A partial explanation for the ascent in these regions is the pattern of the PNA teleconnection as shown in Fig. 9(b): during El Niño events there is anomalous low pressure over the eastern North Pacific Ocean and over the North Atlantic Ocean at around $30^{\circ}-40^{\circ} \mathrm{N}$. Consequently, there is warm advection immediately west of North America and over the subtropical North Atlantic. Anomalous ascent in these regions occurs partly to balance the advective warming with adiabatic cooling.

However, the match between warm advection and ascent is far from perfect. Ascent over the North Atlantic also occurs to the north of the warm advection, and ascent occurs over parts of the eastern North Atlantic where there is anomalous cold advection by the mean flow. The mean advective cooling in these areas is partially offset by anomalous transient-eddy heat flux convergence (not shown) but the ascent must be caused by anomalous vorticity fluxes. Indeed, the ascent in these regions is imperfectly related to the anomalies in the advection of mean vorticity by the mean flow in the upper troposphere (not shown). In contrast, the transient-eddy vorticity flux convergence bears no systematic relationship to the pattern of local ascent, even as it drives the zonal-mean ascent (S03). Further detailed diagnosis of how the temperature and vorticity fluxes combine to cause the observed pattern of ascent and descent is beyond the scope of this paper.

\section{ClimATE MODEL SIMULATION OF TROPICALLY FORCED PRECIPITATION VARIABILITY}

ENSO-forced extratropical precipitation variability has significant social consequences as detailed in, for example, Changnon (2000). As such it is worth examining if these patterns can be simulated in climate models. If they can, then it should be possible to predict them in advance on the time-scale over which tropical Pacific SST anomalies can be predicted. 
(a) Vertical Velocity

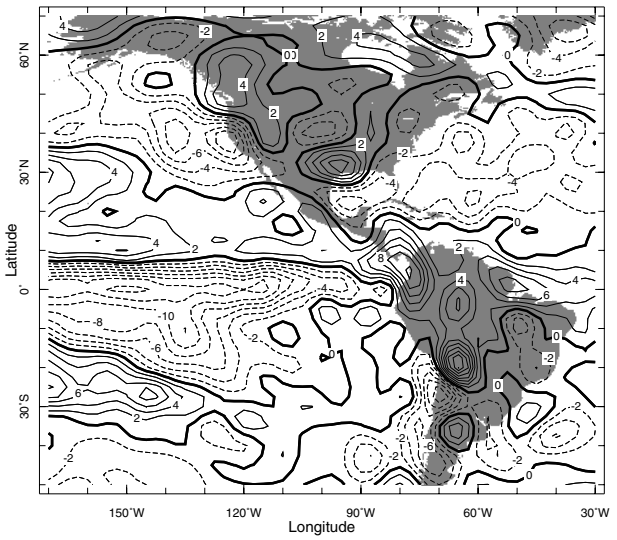

(b) Geopotential Height

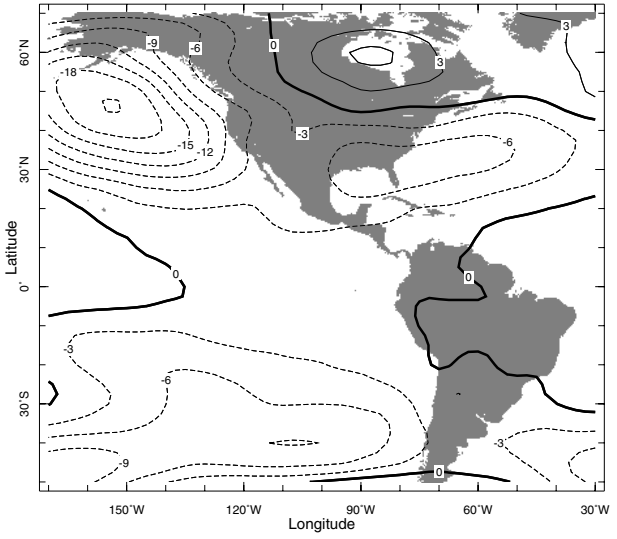

Figure 9. (a) The vertical pressure velocity $\left(\mathrm{mPa} \mathrm{s}^{-1}\right.$ at $\left.700 \mathrm{mb}\right)$ and (b) the $850 \mathrm{mb}$ geopotential height $\left(\mathrm{m}^{2} \mathrm{~s}^{-2}\right)$ regressed onto the wind index for December-May.

Here we analyse results from the mean of a 16-member ensemble of simulations conducted at the Lamont Doherty Earth Observatory with the NCAR Community Climate Model 3 (CCM3, Kiehl et al. (1998)) run at T42 resolution with 18 vertical layers. Each ensemble member used observed SSTs (Rayner et al. 2003) in its surface boundary conditions. The 1979 to 1999 period of the simulations was analysed in a manner identical to the analysis of the Reanalysis.

In Fig. 10 we show the model precipitation anomaly, for the December-May half year, associated with the equivalent in the model ensemble mean of the wind index. The wind index, as in observations, describes a hemispherically symmetric variation of the zonal-mean zonal winds and correlates with the NINO3 index of the SST field imposed on the model at a higher level than in the Reanalysis. This is no doubt due to the isolation of the boundary-forced variability by taking the ensemble mean. The model precipitation anomaly is similar to that observed. Note the ability of the model to get the increased precipitation in the east Pacific to west Atlantic sector in the $\mathrm{NH}$, including 

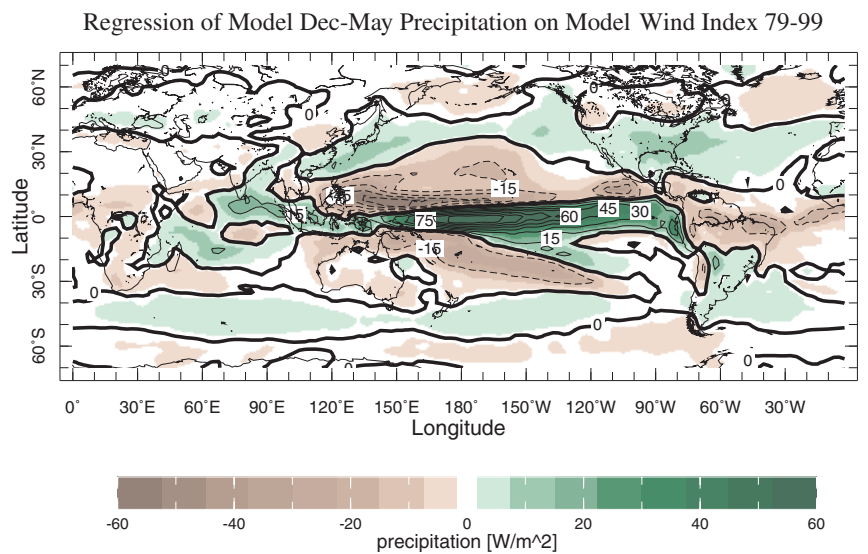

Figure 10. Same as Figure 1(a) except that the precipitation is taken from the ensemble mean of 16 simulations with the NCAR CCM3 model forced by observed SSTs. Units are $\mathrm{W} \mathrm{m}^{-2}$.

the maximum in the south-east United States and the zonally symmetric wet band in the $\mathrm{SH}$.

There are several differences between model and observations. First, the modelled tropical precipitation anomaly is much greater than observed, probably indicating a model error. Secondly, the modelled variability is more zonally symmetric than the observations, especially in the SH. This could be because the ensemble mean isolates the boundary-forced component more than can be done in analysing a mere 22 years of observations or it could be because patterns of precipitation in climate models tend to be more zonally symmetric than in observations. Thirdly, the observed precipitation signal over the Mediterranean and central Asia is either absent or chronically misplaced in the model.

In Fig. 11 we show the mechanisms responsible for the zonal-mean precipitation variations in the model. This should be compared to Fig. 5. In the model, as in observations, the extratropical precipitation anomalies are primarily induced by the MMC. Also, as in observations, the transient-eddy and stationary-wave moisture flux convergences cancel each other. Apparently, the model reproduces the observed mechanisms of ENSO-forced midlatitude precipitation variability.

\section{DiscusSiON}

(a) The proposed mechanism of tropical forcing of zonally and hemispherically symmetric precipitation variability

We are now in a position to summarize the proposed mechanism whereby El Niño causes increased zonal-mean precipitation during the December-May half year in both hemispheres.

An anomalous surface heat flux from the tropical Pacific Ocean to the atmosphere (Sun 2000) warms the atmosphere immediately above. This warming is rapidly spread throughout the tropical atmosphere as a consequence of equatorial wave propagation and because of the inability of the tropical atmosphere to sustain meridional temperature gradients (Schneider 1977). This causes the subtropical jets to strengthen in each hemisphere at the latitude of increased horizontal temperature gradient.

As shown in S03, the changes in the subtropical jet cause perturbations in the meridional gradient of PV that create a region in the midlatitudes where transient eddies 
Dec-May Regression on Model Wind Index (W/m2)

(a) Precipitation and Evaporation

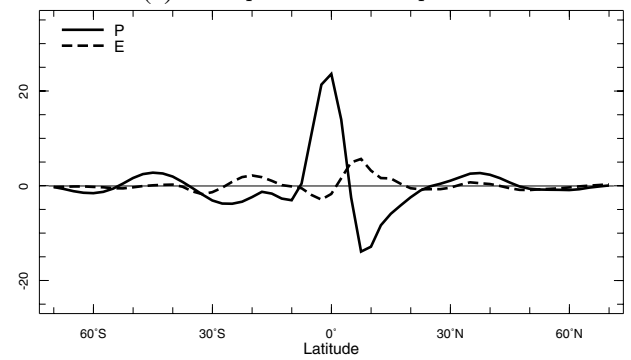

(b) Precipitation, Transient Eddies, and MMC

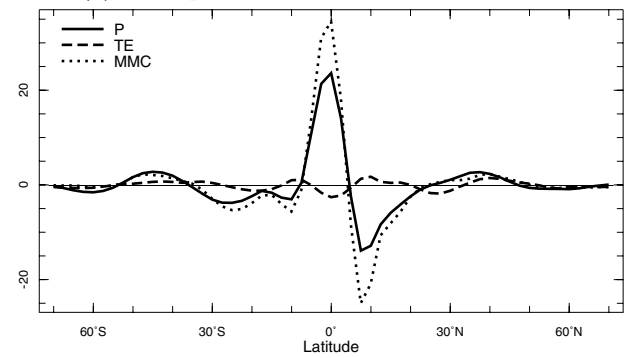

(c) Precipitation, Transient Eddies, and Stationary Eddies

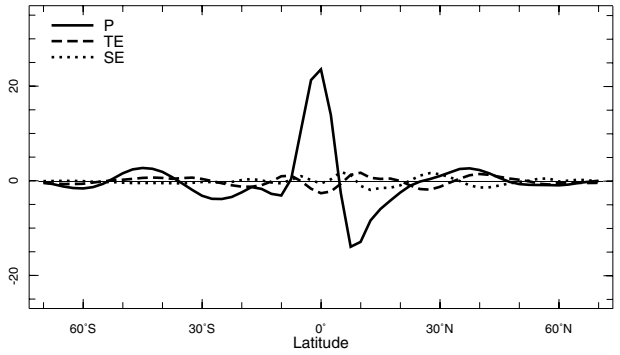

Figure 11. The precipitation, and terms in the vertically integrated moisture budget, regressed onto the wind index for December-May, all quantities taken from the ensemble mean of the 16 simulations with the NCAR CCM3 model. The precipitation is shown in each panel, (a) shows the evaporation, (b) the contributions of moisture convergence by transient eddies and the MMC and (c) the contributions of moisture convergence by transient and stationary eddies. Units are $\mathrm{W} \mathrm{m}^{-2}$.

will adopt a low meridional number. Vertically propagating transient eddies refract away from this area to regions of higher wave number, particularly to the upper troposphere of the subtropics. This creates an anomalous poleward flux of zonal eddy momentum in the subtropical upper troposphere. The meridional gradient of the eddy momentum flux has to be balanced by the Coriolis torque operating on the meridional flow creating equatorward flow in the subtropical upper troposphere. By continuity this is balanced by ascent in midlatitudes. The ascent causes the midlatitudes to cool (S03) and increases midlatitude precipitation.

The anomalies in moisture convergence by transient eddies and stationary eddies cancel each other, maintaining their climatological interrelationship. At the subtropical latitudes of increased vertical shear of the zonal wind and increased meridional temperature gradient (i.e. increased baroclinicity), the transient-eddy activity and transient-eddy 
moisture flux increase. Both decrease further poleward, reflecting an equatorward shift in the storm-tracks. The stationary-eddy moisture flux divergence and convergence also shift equatorward cancelling the transient-eddy contributions.

\section{(b) Precipitation variability in the North American sector}

In addition to the zonally symmetric variability there are important regional variations. As already well established, El Niño events bring increased precipitation to the eastern North Pacific, the west coast of the United States, across the southern United States and to the western North Atlantic Ocean. This broad band of increased precipitation is sustained by anomalous moisture convergence by the mean flow, in its western portions, and by anomalous transient-eddy moisture flux convergence in its eastern portions. However, as for the zonal mean, increased precipitation is more fundamentally caused by anomalous vertical motion, and longitudinal variations of this are associated with anomalous stationary waves propagating from the central Pacific. As part of the PNA teleconnection pattern, there is anomalous low pressure over the subtropical and midlatitude North Pacific and over the subtropical North Atlantic. Warm low-level advection on the eastern and southern sides of these anomalous lows forces ascent and increased precipitation. Ascent can also be forced by both vorticity advection by the mean flow and by transient-eddy vorticity fluxes. As has been argued, these actually drive the zonal-mean ascent and precipitation anomalies, and they also certainly influence the regional anomalies but in a complex way. Much future work needs to be done to unravel the tangle of dynamical processes that cause regional precipitation anomalies in midlatitudes.

\section{(c) Some other relevant ideas on El Niño impacts on transient eddies}

Although the ideas outlined above appear adequate to describe the origins of the observed precipitation anomalies, they may not be complete. In particular it has been argued that strengthening of the subtropical jets on their equatorward side alters the life cycles of baroclinic eddies in the region (Thorncroft et al. 1993). Shapiro et al. (2001) applied this argument to the case of the 1997-1999 ENSO to demonstrate that during the El Niño phase, baroclinic eddies over the eastern tropical Pacific adopted the Life Cycle 2 of Thorncroft et al. (1993) characterized by longevity and greater waviness. That is broadly consistent with our findings here: the extension of the Pacific storm-track into the eastern Pacific and the increased linkage between the Pacific and Atlantic stormtracks is consistent with eddies not decaying in the central Pacific but continuing their life as they propagate further east, while the increased eddy activity, as measured by $\overline{v^{\prime 2}}$, is consistent with increased waviness. Thus it is quite plausible that the changed eddy behaviour over the eastern Pacific-Caribbean-western Atlantic region is not a simple and direct response to increased baroclinicity but also contains the signal of altered baroclinic life cycles. Sorting this out will require considerably more work.

\section{(d) Some unresolved issues}

The mechanism for extratropical precipitation variability presented here (and of temperature variability presented in S03) depends crucially on changes in the strength and latitude of the subtropical jets during ENSO. Despite being a well-observed and robust feature of the ENSO cycle, first noted by Bjerknes (1966) and Arkin (1982), exactly why the jets strengthen (weaken) and move equatorward (poleward) during El Niño (La Niña) remains a matter of mystery. 


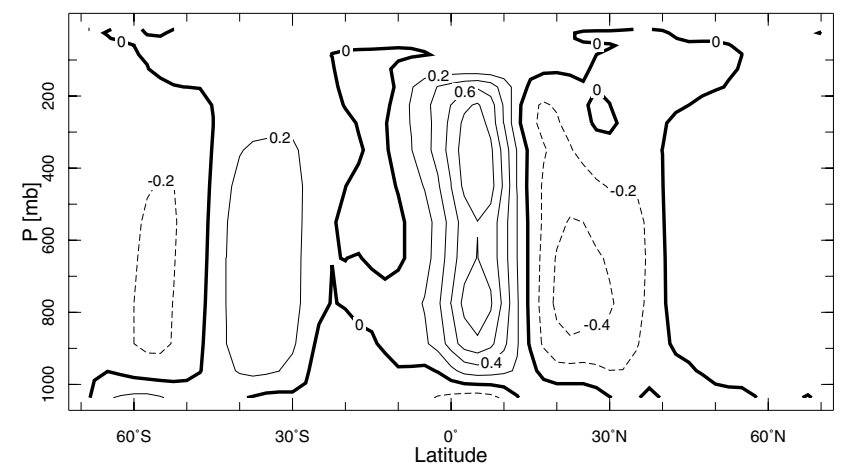

Figure 12. The zonal-mean meridional overturning stream function regressed onto the wind index for the December-May half year. Units are $10^{10} \mathrm{~kg} \mathrm{~s}^{-1}$.

Three possibilities spring to mind. The first is that it is part of the stationary-wave response to the anomalous atmospheric heating in the central tropical Pacific (Gill 1980). This mechanism probably best accounts for why the change in jet strength is most accentuated in the Pacific sector but cannot account for the obvious zonally symmetric component.

Secondly, the jet change may be a response to the meridional shift of the east Pacific ITCZ. Following the reasoning of Lindzen and Hou (1988), when during El Niño the ITCZ moves southward onto the equator and convection increases south of the equator, the Hadley cell in the NH should strengthen, as it does (Fig. 12), and so should the jet on its poleward flank. However, according to Fig. 12, the anomalous Hadley cell does not extend north enough to reach the anomalous northern subtropical jet (Fig. 6(b)) and does not strengthen in the SH at all (see also Waliser et al. (1999))*. Locally this argument may work, for example over the central and eastern Pacific where the latitude shift in near-equatorial precipitation is most pronounced and where the jets strengthen the most. It cannot explain the hemispherically symmetric component.

The third explanation is that the jets strengthen in response to the anomalous oceanto-atmosphere surface heat flux and subsequent tropical warming or cooling. In this case the details of the dynamical adjustment of the atmosphere are unclear but, given that the meridional temperature gradient across the subtropics changes, the jets have to change to maintain thermal wind balance. Because the tropical temperature change has to occur at all longitudes and on both sides of the equator, this explanation seems best able to account for both the zonally and hemispherically symmetric components of the subtropical jet anomalies.

In any case, once a change in the subtropical jets has occurred and influenced the transient-eddy fluxes of heat and momentum, there will be a subsequent adjustment step in which these altered eddy fluxes impact the jets. The equilibrated state is one that couples together the tropical forcing and the transient eddies.

\section{CONCLUSiOnS}

The causes of ENSO-related extratropical precipitation variability have been examined through analysis of the moisture budget contained within the NCEP-NCAR

\footnotetext{
* The anomalous indirect cells in Fig. 11, with rising in the midlatitudes and sinking in the subtropics, are the signature of the eddy-induced MMC described by S03.
} 
Reanalysis and precipitation estimates provided by the Reanalysis and satellite data. The period covered was 1979-2001 to match the period of satellite precipitation data and to only include the period in which the Reanalysis assimilates satellite soundings. It was first shown that the ENSO-related precipitation anomalies, as derived from the Reanalysis moisture budget, were tolerably close to those in the independent satellite estimates. Thus analysis of the Reanalysis moisture budget to examine the causes of the derived precipitation anomalies has relevance to the mechanisms of the observed precipitation anomalies. We focused on the NH winter and spring seasons because ENSO-related SST anomalies peak at this time as do the related precipitation anomalies.

The principal findings are:

(i) El Niño-related precipitation anomalies are quite hemispherically symmetric at all longitudes and have a zonally symmetric component such that the midlatitudes of each hemisphere are moist while the subtropics are dry.

(ii) The zonally symmetric component of the precipitation variability is explained in terms of the strengthening and equatorward shift of the subtropical jets during El Niño. The altered subtropical jets tend to steer upward-propagating transient eddies into the subtropical upper troposphere. This causes eddy-driven ascent in midlatitudes during El Niño events that induces low-level convergence and increased precipitation.

(iii) In the zonal mean the moisture fluxes by the transient and stationary eddies cancel each other such that, in sum, they contribute little to the zonal-mean precipitation anomalies. The cancellation occurs as the latitude of transient-eddy activity shifts equatorward and the pattern of stationary-wave moisture flux convergence and divergence also shifts equatorward.

(iv) Stationary Rossby wave propagation causes important regional departures from symmetry. During El Niño events, eastward extension of the North Pacific subtropical jet stream and southerly flow around a deepened Aleutian Low converge moisture over coastal areas of western North America and offshore. Over the southern United States, anomalous convergence of moisture by transient eddies provides for increased precipitation and is related to the local strengthening of the subtropical jet and associated baroclinicity. Anomalous ascent is the ultimate cause of the increased precipitation and is related to anomalous warm advection around the low-pressure centres of the PacificNorth America pattern, as well as anomalous vorticity fluxes.

(v) In the SH the precipitation anomalies are essentially zonally symmetric and accounted for by interactions between the anomalous mean meridional circulation and transient eddies.

Thus there are two dynamically distinct mechanisms of ENSO-related precipitation anomalies in the extratropics. The division into zonally symmetric and asymmetric mechanisms is, to an uncertain extent, a convenient fiction because they will interact, but it does serve to emphasize that atmosphere dynamics in addition to stationary-wave propagation are required for a full explanation of ENSO-related extratropical precipitation anomalies. Recognition of a dynamical mechanism revolving around interactions between transient eddies and the mean meridional circulation provides a framework for explaining why the atmospheric response to ENSO is more zonally symmetric than expected on the basis of stationary-wave theory alone (Wallace and Jiang 1987; Karoly 1989). Furthermore, recognition of the degree of zonal and hemispheric symmetry, and a means to explain it, will be useful in interpreting modern and, especially, past records of climate variability and change that appear to contain these characteristics (e.g. Stine 1994; Markgraf et al. 2000; Kitzberger et al. 2001). 


\section{ACKNOWLEDGEMENTS}

We would like to thank Naomi Naik and Gus Correa for conducting the climate model simulations and two anonymous reviewers for useful comments. This work was supported, at Lamont, by NOAA grants UCSIO-CU-02165401 and NA16GP2024 and NSF grants ATM-9986515 and ATM-9986072. WR acknowledges support from NSF grant ATM-0237304. This is Lamont Doherty Earth Observatory Contribution Number 6708.

\section{APPENDIX}

\section{The usefulness of the NCEP-NCAR Reanalysis for studying mechanisms of interannual precipitation variability}

In order to determine the mechanisms of ENSO-forced precipitation variability, the various terms in the moisture budget that balance the precipitation-evaporation and convergence of moisture by transient and stationary eddies and by the mean meridional circulation - need to be quantified and related to changes in the atmosphere circulation. This is easy to do with an atmosphere general-circulation model (GCM) but sparsity of data makes it hard to do with confidence using observations. Reanalyses, such as the NCEP-NCAR one, appear promising because they provide complete gridded data at high temporal resolution. Reanalysis data consist of observations from various sources, including satellites in the last two decades, that have been assimilated into a weather forecast model. The assimilation procedure fills in the spatial and temporal gaps in the data.

The precipitation field in the Reanalysis, $P_{\mathrm{NCEP}}$, is that which the model's parametrizations of moist processes give after the assimilation has been completed. Because the model continually assimilates data and is never run to equilibrium, the given precipitation at any place need not balance the sum of the local surface evaporation minus the vertically integrated moisture divergence by the atmospheric flow. The validity of attempts to determine the mechanisms of precipitation variability by examining the different quantities within the Reanalysis moisture budget depends on how large this imbalance is. Bengtsson et al. (2004) have reported on problems with the moisture budget of the ERA40 reanalysis.

Figure A.1 compares the December-May climatological precipitation as given for the period from 1979 to 2001 by the GPCP satellite-gauge observational estimates, $P_{\mathrm{NCEP}}$, and $P_{\mathrm{der}}$, the precipitation estimated from the moisture budget (see section 2). The gross structure of the observations is captured by $P_{\mathrm{NCEP}}$, essentially a validation that the model parametrizations of moist processes can produce a reasonable precipitation field when provided with the best estimates of the atmospheric state. In contrast, $P_{\text {der }}$ contains noticeable errors, especially near steep orography where it can even be negative! Further, there is an excessive noisiness that is obvious despite $P_{\text {der }}$ having been smoothed with a 1-2-1 spatial filter. Also values are too high over the dry regions of the subtropical oceans and over tropical continents. Worrisome for our purposes, $P_{\mathrm{der}}$ has a spurious maximum east of the Rocky Mountains that could occur because too little moisture is wrung out of the air as it passes over the model's low-rise representation of the topography.

To evaluate $P_{\text {der }}$ we used the gridded data and centred differences. Consequently some part of the difference between $P_{\mathrm{NCEP}}$ and $P_{\text {der }}$ is due to the differences in numerical methods used. However, most of the difference between $P_{\text {der }}$ and the precipitation 
Dec-May Precipitation Climatology 1980-2001

(a) GPCP

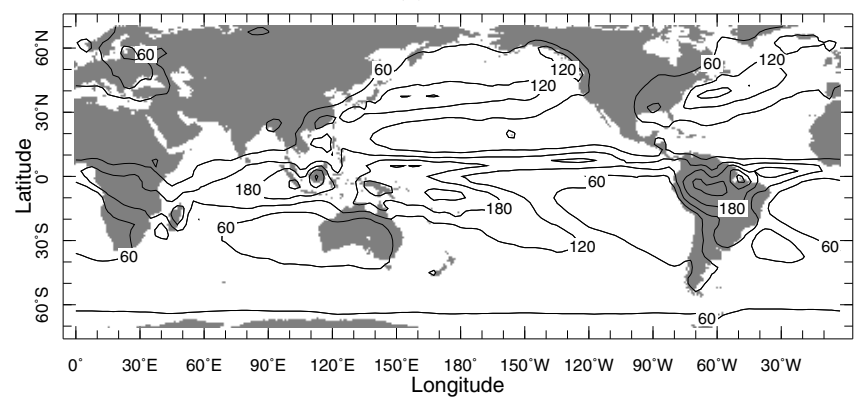

(b) NCEP

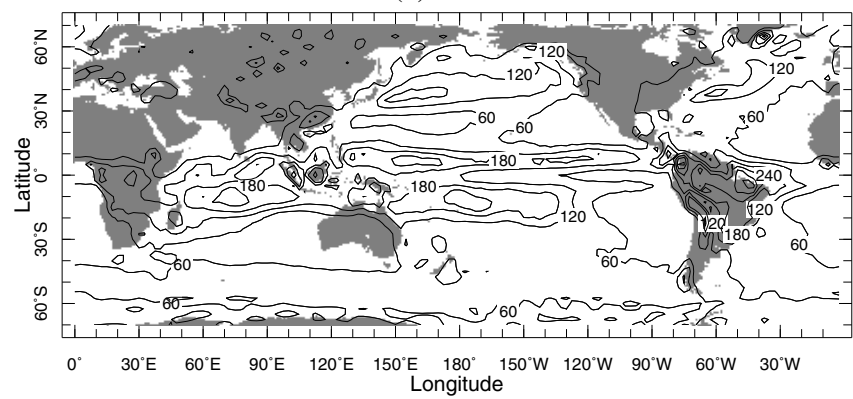

(c) NCEP Derived

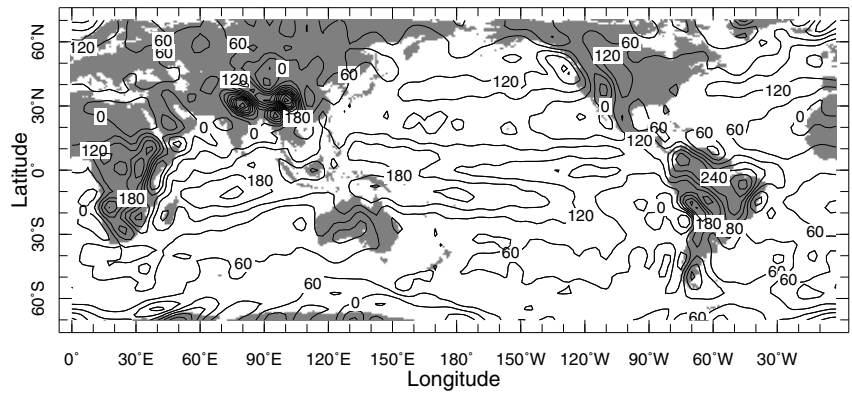

Figure A.1. The climatological precipitation for the December-May half year for (a) the GPCP observations, (b) the NCEP precipitation and (c) the derived NCEP precipitation consistent with the NCEP moisture budget. The precipitation has been converted into $\mathrm{W} \mathrm{m} \mathrm{m}^{-2}$.

given by the Reanalysis, $P_{\mathrm{NCEP}}$, will be because of the imbalance in the Reanalysis moisture budget.

It is possible that despite the clear errors in the version of the Reanalysis precipitation that is consistent with the moisture budget, the interannual variations may be more faithfully represented. Figure A.2 shows the correlation coefficient between the GPCP precipitation for the December-May half year and both $P_{\mathrm{NCEP}}$ and $P_{\mathrm{der}} . P_{\mathrm{NCEP}}$ is highly correlated with the observed precipitation as expected. The correlation with $P_{\text {der }}$ 
Correlation of Dec-May GPCP and Other Precipitation

(a) NCEP

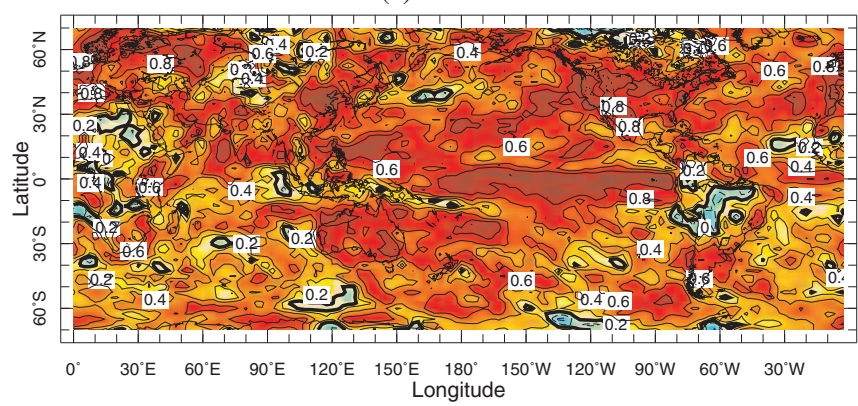

(b) NCEP Derived
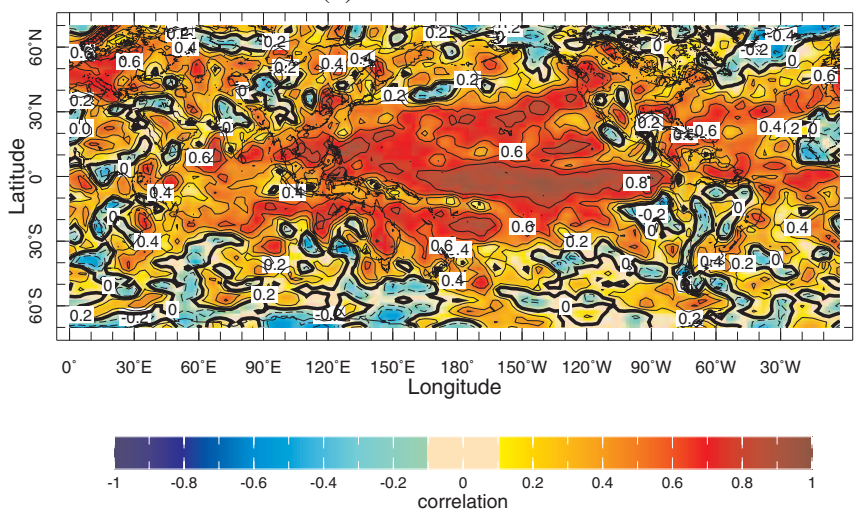

Figure A.2. The correlation between the GPCP observed December-May precipitation and (a) the NCEP precipitation and (b) the derived NCEP precipitation consistent with the NCEP moisture budget.

is also high in the tropics but declines poleward. Nonetheless $P_{\text {der }}$ remains significantly correlated with observations in extensive regions of the midlatitudes.

In section 2 we showed the regression and correlation of $P_{\text {der }}$ on the wind index. In Fig. A. 3 we show the companion plots for $P_{\mathrm{NCEP}}$, to be compared with Fig. 1 . $P_{\mathrm{NCEP}}$ reproduces the significant correlation, seen in the GPCP data, of precipitation in the $\mathrm{NH}$ from the eastern North Pacific across North America to the Atlantic Ocean and also across Asia. It also contains a zonal band of positive correlation in the southern midlatitudes. This shows that, provided with the moisture and circulation fields that we analyse, the physical parametrizations within the NCEP model are capable of producing realistically the aspects of the precipitation variability of interest here. Although we make no further use of $P_{\mathrm{NCEP}}$, this adds to our confidence in the usefulness of the Reanalysis moisture budget.

The ability of the moisture-budget-derived precipitation field to reproduce many aspects of the statistically significant ENSO-forced precipitation variability, as deduced from satellite data, encourages use of the Reanalysis moisture budget to examine the underlying dynamics. 
Relation of NCEP Dec-May Precipitation to Wind Index 80-01

(a) Regression
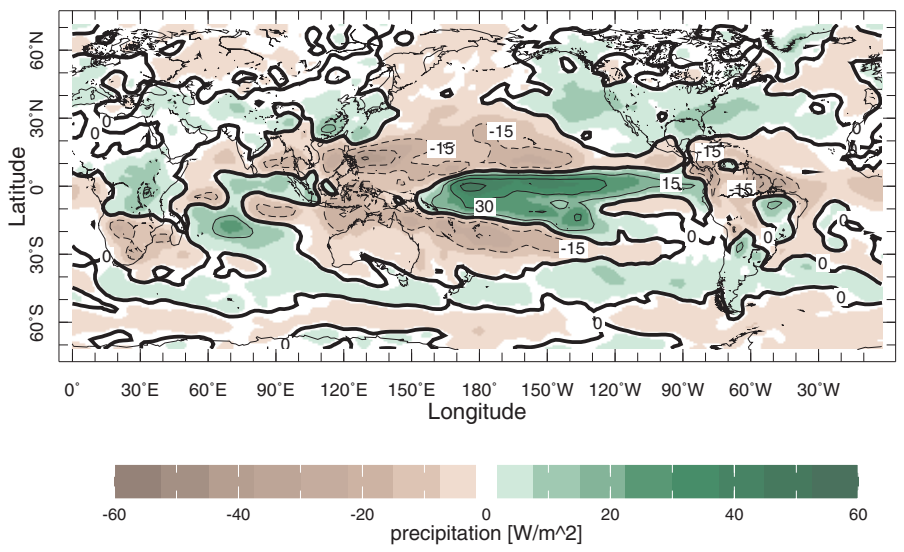

(b) Correlation
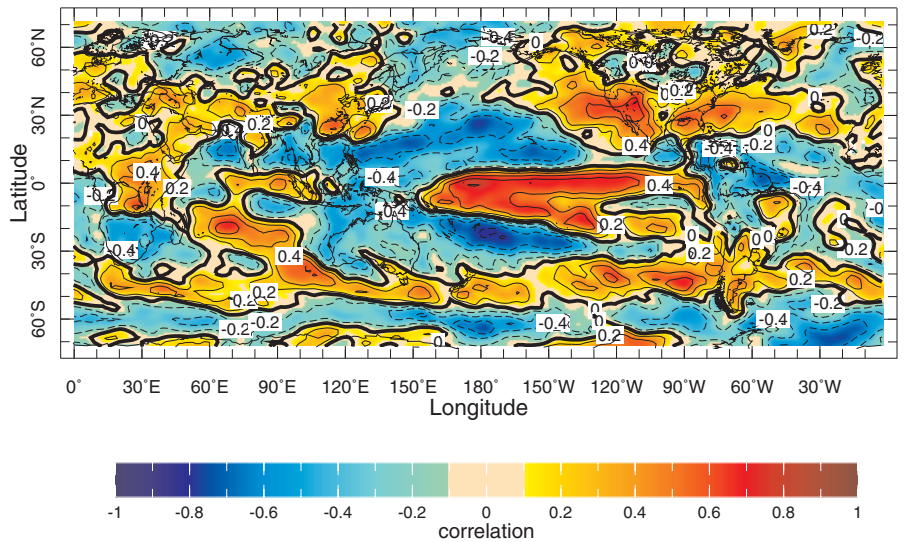

Figure A.3. The (a) regression and (b) correlation between the wind index and the December-May NCEP precipitation, 1980-2001. Units are $\mathrm{W} \mathrm{m}^{-2}$ per unit standard deviation of the wind index.

Aceituno, $\mathrm{P}$.

1988

Arkin, P.

1982

Barlow, M., Cullen, H. and Lyon, B. 2002

Bengtsson, L., Hodges, K. I. and Hagemann, S.

2004

Bjerknes, J.

1966

Changnon, S. A.

Gill, A. E.

Hoerling, M. P. and Kumar, A.

\section{REFERENCES}

On the functioning of the Southern Oscillation in the South American sector. Part 1. Surface climate. Mon. Weather Rev., 116, 505-524

The relationship between interannual variability in the $200 \mathrm{mb}$ tropical wind field and the Southern Oscillation. Mon. Weather Rev., 110, 1393-1404

Drought in central and southwest Asia: La Niña, the warm pool and Indian Ocean precipitation. J. Climate, 15, 697-700

Sensitivity of large-scale atmospheric analyses to humidity observations and its impact on the global water cycle and tropical and extratropical weather systems in ERA40. Tellus, 56A, 202-217

A possible response of the atmospheric Hadley circulation to equatorial anomalies of ocean temperature. Tellus, 18, 820829

El Niño 1997-1998. Oxford University Press, New York

Some simple solutions for heat-induced tropical circulation. Q. J. R. Meteorol. Soc., 106, 447-462

2003 The perfect ocean for drought. Science, 299, 691-694 
Hoerling, M. P. and Ting, M.

1994

Horel, J. D. and Wallace, J. M.

1981

Hoskins, B. J. and Karoly, D. J.

1981

Huffman, G. J., Adler, R. F., Arkin, P., Chang, A., Ferraro, R., Gruber, A. Janowiak, J., McNab, A., Rudolf, B. and Schneider, U.

Kalnay, E., Kanamitsu, R., Kistler, R., Collins, W., Deaven, D., Gandin, L., Iredell, M., Saha, S., White, G., Woollen, J., Zhu, Y., Leetmaa, A., Reynolds, B., Chelliah, M., Ebisuzaki, W., Higgins, W., Janowiak, J., Mo, K. C., Ropalewski, C., Wang, J., Jenne, R. and Joseph, D.

Karoly, D. J.

Kiehl, J. T., Hack, J. J., Bonan, G. B., Boville, B. A., Williamson, D. L. and

Rasch, P. J.

Kiladis, G. N. and Diaz, H. F.

Kistler, R., Kalnay, E., Collins, W., Saha, S., White, G.,

Woollen, J., Chelliah, M., Ebisuzaki, W., Kanamitsu, M., Kousky, V., van den Dool, H., Jenne, R. and Fiorino, M.

Kitzberger, T., Swetnam, T. W. and Veblen, $\mathrm{T}$. $\mathrm{T}$.

Lau, N.-C., Leetmaa, A. and Nath, M. J.

Lee, S. and Kim, H.-K.

Lindzen, R. S. and Hou, A. V.

Markgraf, V., Baumgartner, T. R., Bradbury, J. P., Diaz, H. F., Dunbar, R. B., Luckman, B. H., Seltzer, G. O., Swetnam, T. W. and Villalba, $\mathrm{R}$.

Merkel, U. and Latif, M.

Peixoto, J. P. and Oort, A. H.

Rayner, N. A., Parker, D. E.,

Horton, E. B., Folland, C. K.,

Alexander, L. V.,

Rowell, D. P., Kent, E. C. and

Kaplan, A.

Rodwell, M. J. and Hoskins, B. J.

Ropelewski, C. F. and

Halpert, M. S.
1989

1998

1989

2001

2001

Organization of extratropical transients during El Niño. J. Climate, 7, 745-766

Planetary-scale atmospheric phenomena associated with the Southern Oscillation. Mon. Weather Rev., 109, 813-829

The steady linear response of a spherical atmosphere to thermal and orographic forcing. J. Atmos. Sci., 38, 1179-1196

1997 The Global Precipitation Climatology Project (GPCP) Combined Precipitation Dataset. Bull. Am. Meteorol. Soc., 78, 5-20

The NCEP/NCAR 40-year reanalysis project. Bull. Am. Meteorol. Soc., 77, 437-471

Southern hemisphere circulation features associated with El Niño-Southern Oscillation events. J. Climate, 2, 1239-1252

The National Center for Atmospheric Research Community Climate Model: CCM3. J. Climate, 11, 1131-1149

Global climatic anomalies associated with extremes in the Southern Oscillation. J. Climate, 4, 1069-1090

The NCEP-NCAR 50-year Reanalysis: Monthly means CDROM and documentation. Bull. Am. Meteorol. Soc., 82, 247-267

Inter-hemispheric synchrony of forest fires and the El NiñoSouthern Oscillation. Glob. Ecol. Biogeog., 10, 315-326

Influences of ENSO-induced western Pacific SST anomalies on extratropical atmospheric variability during the boreal summer. J. Climate, in press

The dynamical relationship between subtropical and eddy-driven jets. J. Atmos. Sci., 60, 1490-1503

Hadley circulation for zonally averaged heating centered off the equator. J. Atmos. Sci., 45, 2416-2427

Paleoclimate reconstruction along the Pole-Equator-Pole transect of the Americas (PEP 1). Quat. Sci. Reviews, 19, 125-140

A high resolution AGCM study of the El Niño impact on the North Atlantic/European sector. Geophys. Res. Lett., 29, doi: 10.1029/2001GL013726

Physics of climate. American Institute of Physics, New York

Global analyses of sea surface temperature, sea ice, and night marine air temperature since the late nineteenth century. J. Geophys. Res., 108, doi: 10.1029/2002JD002670

Subtropical anticyclones and summer monsoons. J. Climate, 14, 3192-3211

Global and regional scale precipitation patterns associated with the El Niño/Southern Oscillation. Mon. Weather Rev., 115, $1606-1626$

Precipitation patterns associated with the high index phase of the Southern Oscillation. J. Climate, 2, 268-284 
Ropelewski, C. F. and Halpert, M. S.

Sardeshmukh, P. D. and Hoskins, B. J.

Schneider, E. K.

Schubert, S. D., Suarez, M. J., Pegion, P. J., Koster, R. D. and Bacmeister, J. T.

Seager, R., Harnik, N., Kushnir, Y., Robinson, W. and Miller, J.

Seager, R., Murtugudde, R., Clement, A. and Herweijer, C.

Seager, R., Murtugudde, R., Naik, N., Clement, A., Gordon, N. and Miller, J.

Shapiro, M. A., Wernli, H., Bond, N. A. and Langland, R.

Sun, D.-Z.

Stine, S.

Thorncroft, C. D., Hoskins, B. J. and McIntyre, M. E.

Trenberth, K. E. and Guillemot, C. J.

Trenberth, K. E. and Stepaniak, D. P.

Trenberth, K. E., Branstator, G. W., Karoly, D., Kumar, A.,

Lau, N.-C. and Ropelewski, C.

Waliser, D. E., Shi, Z., Lanzante, J. R. and Oort, A. H.

Wallace, J. M. and Gutzler, D. S.

Wallace, J. M. and Jiang, Q.

Wang, H. and Ting, $M$.

2000

Webster, P. J.
1996

1988

1977

2004

$2003 a$

$2003 b$

$2003 c$

1994

1998
Quantifying Southern Oscillation-precipitation relationships. J. Climate, 9, 1043-1059

The generation of global rotational flow by steady idealized tropical divergence. J. Atmos. Sci., 45, 1228-1251

Axially symmetric steady-state models of the basic state for instability and climate studies. Part II. Non-linear calculations. J. Atmos. Sci., 34, 280-296

Causes of long-term drought in the United States Great Plains. J. Climate, 17, 485-503

Mechanisms of hemispherically symmetric climate variability. J. Climate, 16, 2960-2978

Why is there an evaporation minimum at the Equator? J. Climate, 16, 3793-3802

Air-sea interaction and the seasonal cycle of the subtropical anticyclones. J. Climate, 16, 1948-1966

The influence of the 1997-99 El Niño Southern Oscillation on extratropical baroclinic life cycles over the eastern North Pacific. Q. J. R. Meteorol. Soc., 127, 331-342

The heat sources and sinks of the 1986-87 EI Niño. J. Climate, 13, 3533-3550

Extreme and persistent drought in California and Patagonia during mediaeval time. Nature, 369, 546-549

Two paradigms of baroclinic-wave life-cycle behaviour. Q. J. R. Meteorol. Soc., 119, 17-55

Evaluation of the atmospheric moisture and hydrological cycle in the NCEP/NCAR reanalyses. Clim. Dyn., 14, 213-231

Seamless poleward atmospheric energy transports and implications for the Hadley circulation. J. Climate, 16, 3706-3722

Progress during TOGA in understanding and modeling global teleconnections associated with tropical sea surface temperatures. J. Geophys. Res., 103, 14291-14324

The Hadley circulation: assessing NCEP/NCAR reanalysis and sparse in-situ estimates. Clim. Dyn., 15, 719-735

Teleconnections in the geopotential height field during the northern hemisphere winter. Mon. Weather Rev., 109, 784-812

On the observed structure of the interannual variability of the atmosphere/ocean climate system. Atmospheric and Oceanic Variability, H. Cattle, Ed., Royal Meteorological Society/American Meteorological Society, 17-43

Covariabilities of winter U.S. precipitation and Pacific sea surface temperatures. J. Climate, 13, 3711-3719

Mechanisms determining the atmospheric response to sea surface temperature anomalies. J. Atmos. Sci., 38, 554-571 